\title{
AN IMPROVED MODEL FOR WASTE MANAGEMENT FROM FISH FARMING IN TIDAL RIVER
}

\author{
Tran Thi Ngoc TRIEU ${ }^{1}$ and Minjiao LU² \\ ${ }^{1}$ Member of JSCE, Dept. of Civil and Environmental Engineering, Nagaoka University of Technology (1603-1, \\ Kamitomioka, Nagaoka, Niigata 940-2188, Japan) \\ 2 Member of JSCE, Professor, Dept. of Civil and Environmental Engineering, Nagaoka University of Technology \\ (1603-1, Kamitomioka, Nagaoka, Niigata 940-2188, Japan)
}

\begin{abstract}
This paper describes the improvements of the 3D model proposed by Trieu et al. (2010). The model was applied to simulate the pollutant transport from fish cages (group of cages located closely together that was assigned as the single point source of pollution discharge) in the river system. In contrast, the pollution discharge from both the pond culture and the cage culture was considered in the present study. Moreover, the complete suspension was modeled by calculating the concentration of particle wastes load from riverbed. Furthermore, the conservation of simulation was ensured by using the finite volume method instead of the finite difference method to solve the 2D flow field. The improved model simulated nutrient discharge from the intensive Pangasius farming in the Mekong Delta, Vietnam. The simulated output was verified with the observed data. A good agreement between the observed and simulated data proves that the improved model could help decision makers for better planning and monitoring purposes.
\end{abstract}

Key Words: Nutrients, simulation, fish farming, multipoint source, numerical model.

\section{INTRODUTION}

Pangasius production in the Mekong Delta, Vietnam is one of the biggest freshwater aquaculture industries globally. Fish are farmed mainly in earthen ponds. The treatment of effluent is required by national legislation. However it is nearly impossible in practice. Most fish farms are small scale and the land used for fish ponds is very expensive. Fish farms here having sedimentation ponds are less than $10 \%{ }^{1)}$. And large volume of effluent from fishponds was discharged directly into rivers and canals. Besides, fish farming in cages located along two branches of the Mekong River where waste cannot be treated have been considered as a source of pollution. The scientific literature $^{1-3)}$ has identified the main environmental impact from fish farms due to direct discharge of effluent to surface water. Therefore, there is a need of predictive tools able to assess whether or not the fish farming activity can result in a potential impact on the surrounding environment.

Numerical models can be used to perform environmental impact predictions and test different scenarios. The interest in monitoring and management of aquaculture wastes with mathematical models has been rapidly increasing in time as a consequence ${ }^{4-7)}$. Most models were applied for coastal water only. Keeping this in mind, we introduced the three-dimensional (3D) pollutant transport model for tidal river and its variability in simulating different aquaculture wastes $^{8)}$

In the present study, we tried to improve the model proposed in our previous study ${ }^{8)}$. The improvements and their importance assessment have been implemented in three areas: (a) a scheme to deal with multipoint source for simulating nutrients discharge from both pond culture and cage culture was introduced, (b) an experimental formula was added to calculate accumulation of particle wastes at river bed and (c) improving our methodology by using the finite volume method to solve the governing equations in order to guarantee conservation of the simulation.

The focus of this study is to simulate towards a 


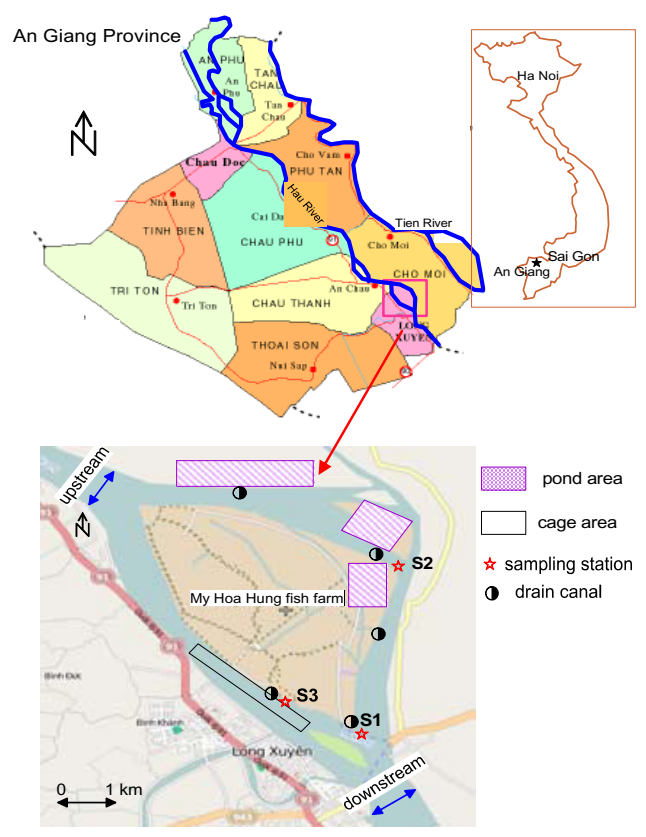

Fig.1 My Hoa Hung fish farm, An Giang province.

more realistic scenario. Most present aquaculture models consider for one source point only ${ }^{4-7)}$. In the previous model, we considered a group of cages which located close together on the river as one source. This improved model introduced an application of multipoint source for aquaculture purposes that could help to simulate at the same time discharge from both ponds and many cages which spread over a large area. The second improvement of this study is that dispersion of particulate waste at the bottom was improved by adding an experimental formula of suspended waste concentration suggested by Van Rijn ${ }^{9}$. On the other hand, fish feces are the major source of particulate nutrients inside pond and the settling velocity values specifically for fish feces from pond represents key parameters for fishpond waste dispersion model. Finally, we recognized that finite difference method for solving 2D flow, as we did in Trieu et $a l^{8)}$, is insufficient to ensure the conservation and accuracy of calculation. Using the finite volume method to solve the governing equations is appropriate to simulation.

In this study, the improved model was applied to simulate flow velocities and spatial contribution of both dissolved and particulate forms of total nitrogen and total phosphorus which discharged by Pangasius farming in the Mekong Delta. The model was verified with observed data.

\section{METHOD}

\section{(1) Study area}

The simulations were carried out for the My Hoa Hung fish farm located in My Hoa Hung commune, An Giang province (Fig.1). There are many floating cages and ponds in this area (about 300 cages and 466.16 ha pond ${ }^{10)}$ ). Bathymetry was surveyed by the Southern Institute of Water Resources Research (SIWRR) in 2004. The dimension of the study area is $10 \mathrm{~km} \times 5 \mathrm{~km}$, the river depth is from $0 \mathrm{~m}$ to $25 \mathrm{~m}$. The calculation domain was rotated about $-35^{\circ}$ in order to assign boundary condition at sections which are perpendicular to the flow direction as well as y axis. Then it was divided into $25 \mathrm{~m} \times 25 \mathrm{~m}$ cells in a horizontal plane and ten layers in vertical direction.

\section{(2) Model}

The governing equations for the $2 \mathrm{D}$ shallow water flow model:

$$
\begin{aligned}
& \frac{\partial \eta}{\partial t}+\frac{\partial q_{x}}{\partial x}+\frac{\partial q_{y}}{\partial y}=0 \\
& \frac{\partial q_{x}}{\partial t}+\frac{\partial U q_{x}}{\partial x}+\frac{\partial V q_{y}}{\partial y}+g h \frac{\partial \eta}{\partial x}-f q_{y} \\
& \quad+f r \frac{q \cdot q_{x}}{h^{2}}-\frac{\tau_{w x}}{\rho}=0 \\
& \frac{\partial q_{y}}{\partial t}+\frac{\partial U q_{y}}{\partial x}+\frac{\partial V q_{y}}{\partial y}+g h \frac{\partial \eta}{\partial y}+f q_{x} \\
& \quad+f r \frac{q \cdot q_{y}}{h^{2}}-\frac{\tau_{w y}}{\rho}=0
\end{aligned}
$$

Where: $U, V=$ two components of depth averaged velocity in $\mathrm{x}, \mathrm{y}$ direction; $h=\eta-z_{b}=$ total water depth; $q_{x}, q_{y}=$ two components of unit discharge $\left(q_{x}=U h ; q_{y}=V h\right.$ and $\left.q=\sqrt{q_{x}^{2}+q_{y}^{2}}\right) ; t=$ time; $g=$ gravity acceleration; $\eta=$ water surface elevation; $z_{b}=$ riverbed elevation; $\rho=$ water density; $f$ =Coriolis coefficient; $f_{r}=$ bed friction coefficient; $\tau_{w x}, \tau_{w y}=$ wind stress at free surface.

The governing equations were discretized in the computational domain using finite volume technique. In the alternate grid, equations (1)-(3) with boundary conditions were solved numerically over corresponding control volumes (Fig.2) to get water level and two unit discharge components. Then a 3D flow-field was derived by distributing logarithmically 2D flow field along water depth and the vertical velocity was derived from the integral of the 3D continuity equation (see Trieu et $a l^{8}$ ) for more details about the model).

Waste concentration was calculated by solving its full 3D transport equation by the finite volume method with ADI scheme of Douglas - Gunn ${ }^{11)}$ in the "sigma" transformed co-ordinate system. 


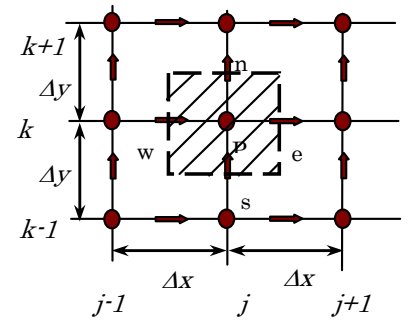

a) Control volume of $\eta$

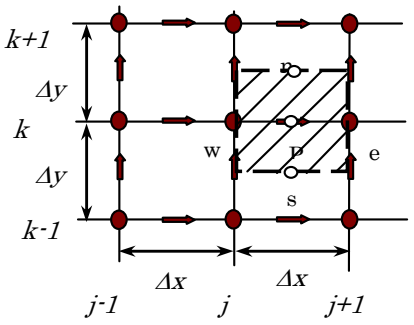

b) Control volume of $\mathrm{q}_{\mathrm{x}}$

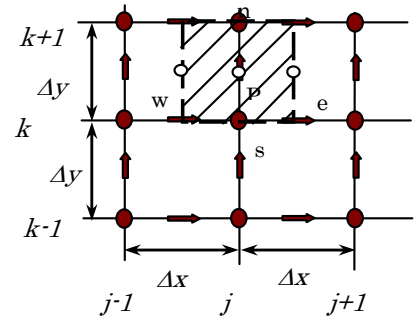

c) Control volume of $q_{y}$

Fig. 2: Control volumes

$$
\begin{aligned}
& \frac{\partial q_{C}}{\partial t}+\frac{\partial}{\partial x}\left(u q_{C}-D A_{C} \frac{\partial}{\partial x}\left(\frac{q_{C}}{D}\right)\right)+ \\
& \frac{\partial}{\partial y}\left(v q_{C}-D A_{C} \frac{\partial}{\partial y}\left(\frac{q_{C}}{D}\right)\right)+ \\
& \frac{\partial}{\partial \sigma}\left(\left(\omega-\frac{\omega_{s}}{D}\right) q_{C}-\frac{K_{C}}{D} \frac{\partial}{\partial \sigma}\left(\frac{q_{C}}{D}\right)\right)=D . S
\end{aligned}
$$

Where: $q_{C}=D . C$ - pollutant discharge; $C=$ waste concentration; $D=\eta+h ; u, v$ and $\omega=$ velocity in the $x, y$ and $\sigma$ direction. $A_{C}, K_{C}=$ eddy diffusivity coefficients in horizontal and vertical direction; $\omega_{\mathrm{s}}=$ settling velocity; $S=$ source term. Convection terms of pollutant transport equation were interpolated by a centered scheme.

The settling velocities of Pangasius nutrients discharge are not investigated. Therefore, a value of $0.48 \mathrm{~cm} / \mathrm{s}$ from the already validated settling velocity of benthic waste of sea bream ${ }^{12)}$ was used for particulate nutrient that was released from fishponds. Beside that, a decay rate for nutrients suggested by Lefebvre et al. $^{13)}$ was implemented. The estimated decay rates for nitrogen and phosphorus at $25^{\circ} \mathrm{C}$ were 0.040 day $^{-1}$ and 0.017 day $^{-1}$, respectively.

Equation (4) was solved with following boundary conditions:

-Free surface boundary: At $z=\eta$, no pollutant flux goes through the surface.

-Bottom boundary: At interface of bed layer $z=z_{b}+a$, a pollutant flux going through the interface was defined by Van Rijn ${ }^{14)}$ : $D_{b}-E_{b}=\omega_{s}\left(C_{b}-C_{b^{*}}\right)$

In which: $D_{b}=$ fish waste accumulated in the bottom; $E_{b}=$ fish waste loaded from bottom; $C_{b}, C_{b^{*}}=$ current concentration and saturated concentration in the bed surface. Last time, we had to use the only value available in the literature for $C_{b^{*}}$. In this study, considering particle nutrients from fishponds as bottom sediment, a simple formula suggested by Van Rijn ${ }^{9)}$ was used. This will help to simulate various particulate aquaculture wastes by changing a few parameters.

$$
C_{b^{*}}=0.015 \frac{d_{50}}{a} \frac{T^{1.5}}{D_{*}^{0.3}}
$$

$T=\left(\tau_{b}-\tau_{b, c r}\right) / \tau_{b, c r} \quad ; \quad D_{*}=d_{50}\left[(s-1) g / v^{2}\right]^{1 / 3}$

Where: $d_{50}=$ mean diameter of waste particle; $s=$ density of waste particle; $\tau_{b, c r}=$ the critical shear stress Shields; $\tau_{b}=$ the bed shear stress.

-Solid boundary: the waste flux was set to zero.

-Open boundary: A value of waste concentration was defined at the inlet. At outlet boundary: a zero-gradient condition of concentration was used.

The time step was reduced as: $\Delta t=1 \mathrm{~s}$ to ensure the model's stability while solving water surface and velocities, and to speed up calculation, the time step for solving transport equation was five seconds used.

In this paper, we made a simulation for dry season from 24 April 2007 to 27 April 2007 when fish are at growth in the background of the least discharge in the Mekong River and high production of Pangasius of the Mekong Delta (about 1,200 thousand tons in $2007^{15)}$ ).

Due to the lack of gauged hydrodynamics data in the study location, we decided to make an offline coupling with a $1 \mathrm{D}$ flow model $-\mathrm{MK}^{16}$ ) for a larger scale using observed hydrodynamic flow data to generate boundary conditions for simulation. This mainly implies that the open boundary conditions are improved by applying calculated results verified by realistic current measurements. It is a good alternative for some areas that have no gauge data.

-At upstream boundary, a discharge time series was used. The discharge data which were redistributed as: $q_{n i}=Q(t) \cdot h_{i}^{5 / 3} /\left(\Delta x \cdot \Sigma h_{i}^{5 / 3}\right)$ and $\partial q_{\tau} / \partial n=0$ assigned to grid node $i$ at upstream cross section. -At downstream boundary, water level $\eta=\eta(t), \partial q_{\tau} / \partial n=0$ and $\partial q_{n} / \partial n=0$ were 
Table 1 Nutrients loading from fish farm.

\begin{tabular}{|l|r|c|}
\hline \multicolumn{1}{|c|}{ Parameters } & Value & Unit \\
\hline \hline \multicolumn{1}{|c|}{ From ponds } & & \\
Total ponds area & 466.16 & $\mathrm{ha}$ \\
Mean yield ${ }^{2}$ & 300 & $\mathrm{t} / \mathrm{ha}$ \\
Dissolved nitrogen & 27.63 & $\mathrm{mg} / \mathrm{l}$ \\
Dissolved phosphorus & 8.78 & $\mathrm{mg} / \mathrm{l}$ \\
Particulate nitrogen & 2810 & $\mathrm{mg} / \mathrm{kg}$ \\
Particulate phosphorus & 885.3 & $\mathrm{mg} / \mathrm{kg}$ \\
\hline \multicolumn{1}{|c|}{ From cages $_{\text {Total cages }}$} & 300 & $\mathrm{cages}$ \\
Volume & $500-1000$ & $\mathrm{~m}^{3} / \mathrm{cage}$ \\
Mean yield & $50-100$ & $\mathrm{t} / \mathrm{cage}$ \\
Total Nitrogen & \\
Total Phosphorus & 46.8 & $\mathrm{~kg} / \mathrm{t}$ \\
Dissolved nitrogen & 18.4 & $\mathrm{~kg} / \mathrm{t}$ \\
Dissolved phosphorus & 36.5 & $\mathrm{~kg} / \mathrm{t}$ \\
Particulate nitrogen & 3.86 & $\mathrm{~kg} / \mathrm{t}$ \\
Particulate phosphorus & 10.3 & $\mathrm{~kg} / \mathrm{t}$ \\
\hline
\end{tabular}

used.

In which, $Q(t), \eta(t)$ were generated by MK4 and $h_{i}$ - water depth at node $i, \tau, n$ - tangential and normal direction at boundaries.

\section{(3) Nutrients input}

Nitrogen and phosphorus discharged from fish farming exist in both soluble waste and particulate waste through dissolved nutrients, feces and uneaten food. Experimental data of nitrogen and phosphorus concentration at the study site were obtained through Hanh ${ }^{17)}$. Exchanged water and sludge in typical ponds and 3 locations surrounding in My Hoa Hung fish farming S1, S2 and S3 (Fig.1) were sampled in dry season 2007. Exchanged water sample was analyzed for dissolved nitrogen and phosphorus according to $\operatorname{APHA}(1998)^{18)}$. Sludge sample was analyzed for particulate nitrogen and phosphorus by Vietnamese Standard TCVN 7209:2000 ${ }^{19)}$.

In pond culture, pellet feeds are used. In cage culture, farm-made feeds are used. De Silva ${ }^{5)}$ found that nitrogen discharge levels for farm made feeds have a median of $46.8 \mathrm{~kg} / \mathrm{ton}$ fish; whilst phosphorus discharge levels for farm made feeds have a median of $18.4 \mathrm{~kg} / \mathrm{ton}$ fish. The ratio of dissolved nitrogen and phosphorus for Pangasianodon hypophthalmus farming is not known. Ackefors and Enel1 ${ }^{20)}$ estimated that $78 \%$ of nitrogen released is dissolved and $22 \%$ is particulate, $21 \%$ of phosphorus is dissolved while the rest is particulate in salmonid farm. So these values were used (Table 1).

The multipoint sources were assigned by discharge from pond to river taking place periodically at drain canals (five places were taken

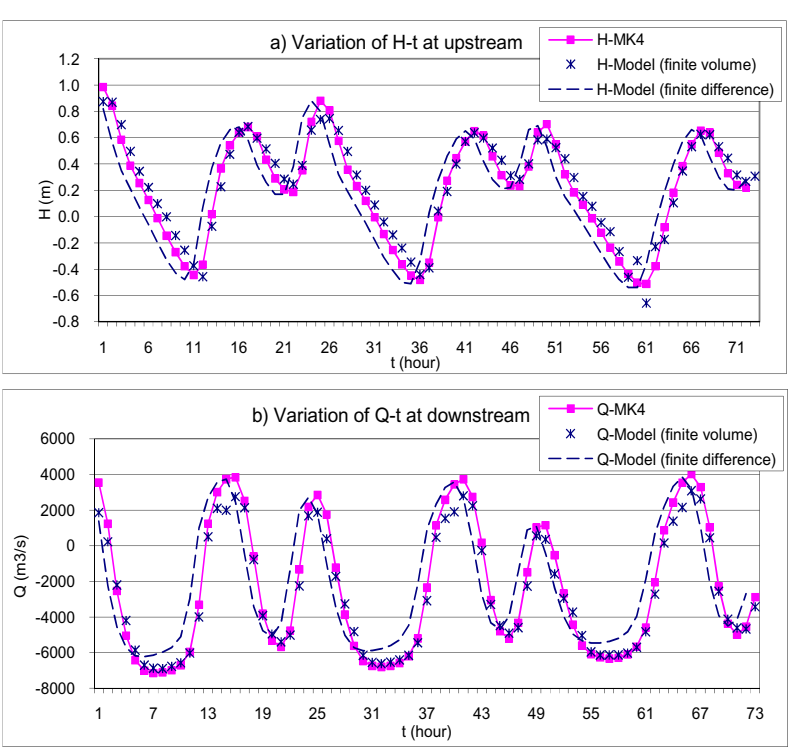

Fig.3 Comparison of results of flow between the proposed model and MK4 (see in Fig. 1 for locations of upstream and downstream site).

in account for discharge points from pond culture) (Fig.1) and considering each cage as one source point which released waste continuously.

\section{RESULTS AND DISCUSSIONS}

\section{(1) Flow field}

Due to lack of field data, flow simulation results were compared with results of MK4. In Fig.3, there was a good agreement in comparison of water level at upstream and (Q- $t$ ) at downstream site between the model and MK4 results. Moreover, a better reproduction of flow simulation by using the finite volume method was showed in this figure.

The tidal effect was expressed clearly with flow velocity distribution in simulation (Fig. 4).

\section{(2)Nutrient dispersion}

The concentration of nitrogen and phosphorus in simulation were agreed with those of field data. The highest simulated concentrations for dissolved nitrogen were $39 \mathrm{mg} / \mathrm{l}$, for dissolved phosphorus were $12.5 \mathrm{mg} / 1$ (Table 2). Proposed standard by WWF (World Wildlife Fund) for total ammonia nitrogen and phosphorus was $10 \mathrm{mg} / 1$ and $5 \mathrm{mg} / 1$ respectively ${ }^{21}$. It showed that the nutrients levels in the fish farm section were high. The enrichment of water bodies with nutrients, in particular nitrogen and phosphorus, has the potential to cause eutrophication in river. Values of nitrogen and phosphorus concentration in water column in farming area depended on tide process and schedule of discharge waste (Fig. 5a,b). Wastewater from ponds was exchanged during high water level. The results presented the extension of the impacted area 
Table 2 Comparison between calculated and observed nutrient concentration in fish farming.

\begin{tabular}{|l|l|l|l|l|}
\hline \multicolumn{1}{|c|}{ Indicators } & Station & $\begin{array}{l}\text { Calculated } \\
\text { Min - Max }\end{array}$ & Observed & Unit \\
\hline \hline 1/ Dissolved & $\mathrm{S} 1$ & $5.6-39.0$ & 39.5 & \\
nitrogen & $\mathrm{S} 2$ & $2.2-35.0$ & 32.0 & $\mathrm{mg} / 1$ \\
& $\mathrm{~S} 3$ & $4.4-31.0$ & 36.0 & \\
\hline 2/ Dissolved & $\mathrm{S} 1$ & $3.6-11.5$ & 10.9 & \\
phosphorus & $\mathrm{S} 2$ & $1.0-12.5$ & 11.2 & $\mathrm{mg} / 1$ \\
& $\mathrm{~S} 3$ & $1.0-3.5$ & 2.3 & \\
\hline 3/ Particle & $\mathrm{S} 1$ & $1800-1900$ & 1817.2 & \\
nitrogen & $\mathrm{S} 2$ & $800-1000$ & 1044 & $\mathrm{mg} / 1$ \\
& $\mathrm{~S} 3$ & $1100-1700$ & 1591 & \\
\hline 4/ Particle & $\mathrm{S} 1$ & $140-170$ & 176.9 & \\
phosphorus & $\mathrm{S} 2$ & $270-320$ & 329.2 & $\mathrm{mg} / 1$ \\
& $\mathrm{~S} 3$ & $120-140$ & 117.9 & \\
\hline
\end{tabular}

with respect to the position of discharge point. The concentrations of nitrogen and phosphorus at locations S1, S2 and S3 were increasing with rising tide. Then these concentrations began to decrease and got minimum value on ebb tide because waste was tided down and diffused away. This process was repeated when it was flood tide again.

When sludge was periodically pumped out, particulate nutrients from sludge settled quickly and deposited on the riverbed. It was not frequent but the concentration of nutrients in discharged sludge was much higher than in daily exchanged water. Development of nutrients accumulated on the riverbed was showed in Fig 5c,d. Particulate nutrients accumulate on a smaller area within $200 \mathrm{~m}$ range from the discharge point. Maximum concentrations of nutrients on riverbed are $1900 \mathrm{mg} / \mathrm{l}$ and $320 \mathrm{mg} / \mathrm{l}$ for particulate nitrogen and particulate phosphorus, respectively. Therefore pumping out sludge to surrounding surface water could cause an environment problem.

In simulation, though 300 cages distributed along the riverbank, nutrients in cage culture were continuously released with concentration lower than nutrients from ponds. So it was easily diluted by the river flow. The environmental impact of nutrients released from cage culture is not dominant. The fishpond effluent released twice a day contributes a larger effect to water pollution in river. However the concentration quickly decreased after stopping discharge due to large river and high flow velocity of river.

In previous study, we could not simulate discharge for whole fish farm. We just considered pollutant transport from a group of cages. And the preliminary results did not reflect the effluent discharges at fish farming area of 300 cages and over 466 ha of fishpond. Thanks to the improved model presented here, both discharge from pond

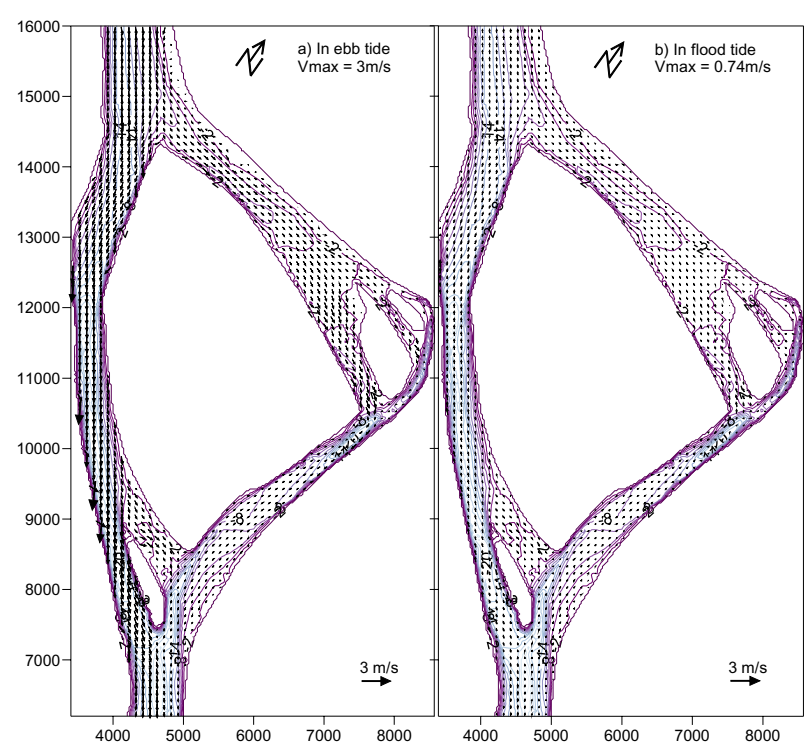

Fig.4 Depth contour and velocity distribution in farming area.

area and cage area with different release modality (continuous and periodical) were included. Both the hydrodynamics and the dispersion in the study area were better reproduced that leads to more realistic results. This is mainly due to adding of multi-point source, the mass conservation of the finite volume method and the choice of Van Rijn's formula for particulate waste which loaded from the riverbed. This model allows the estimation of dissolved nutrients discharged from fish farm and the degree as well the location of the potential impact from particulate nutrients on the riverbed more exactly. According to the simulated results, the pollution situation was local and effect was temporary. There is a need to mitigate the environmental problem step by step because nutrients concentration was high. Firstly the levels of waste concentration should be limited and then suitable techniques should be studied to treat wastewater.

\section{CONCLUSION}

Aquaculture is the most rapid growth industry in the world that produces an immediate concern. Hence it is necessary to develop tools to predict the environmental impacts arising from intensive fish farms. In this paper, we improved the capability of the 3D model that has already proposed in a previous work ${ }^{8)}$. We developed both a more realistic setup of discharge sources and a full suspension model that revealed its ability to simulate different scenarios by switching suitable parameters.

An actual state of nutrients discharge in My Hoa Hung fish farm was simulated. The results showed that nutrient loadings were high. Directly discharge fish effluent to the Mekong River is an environmental problem. Monitoring water quality 

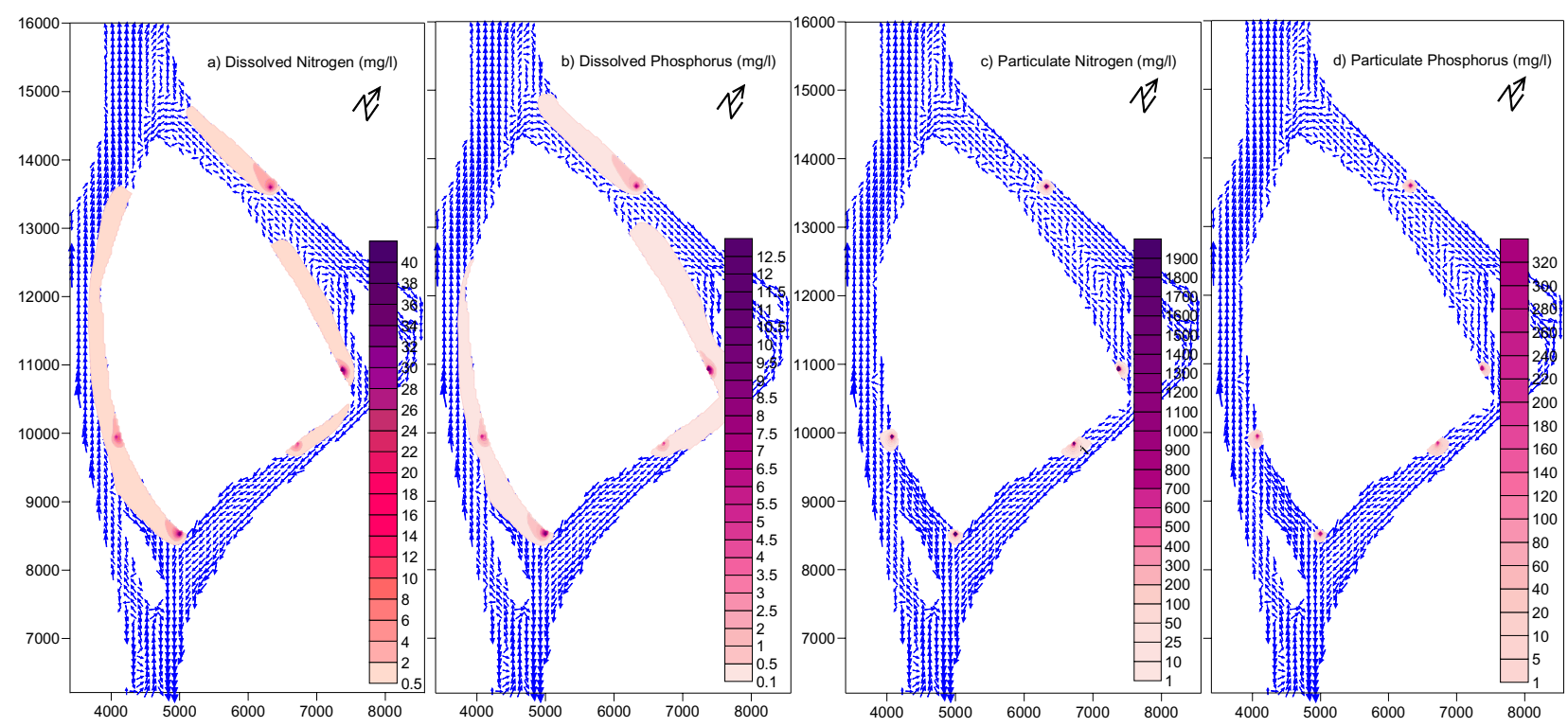

Fig.5 Concentration of nutrients in farming area.

in fish farming was very necessary and the numerical model illustrated an economical solution in waste management from fish farm. The model presented here is able to improve the decision making processes and it may be successfully used for planning and monitoring purposes.

\section{REFERENCES}

1) Anh, P. T.: Water pollution by Pangasius production in the Mekong Delta, Vietnam: causes and options for control, Aquaculture Research, pp.1-21, 2010.

2) Da, C. T. and Berg, H.: Catfish (Pangasius Hypothalamus) Farming System, Vietnam.., LAP LAMBERT Academic Publishing AG\&Co. KG, Germany, 128pp, 2009.

3) De Silva, S. S., Ingram, B. A., Phuong T. N., Tam M. B., Gooley, G. J. and Turchini, G. M.: Estimation of Nitrogen and Phosphorus in Effluent from the Striped Catfish Farming Sector in the Mekong Delta, Vietnam, Ambio, Vol. 39, pp.504-514, 2010.

4) Wu, R. S. S., Shin, P. K. S., MacKay, D. W., Mollowney, M. and Johnson, D.: Management of marine fish farming in the sub-tropical environment: a modeling approach, 2nd Aquaculture, Vol.174, pp.279-289, 1999.

5) Kishi, M. J., Uchiyama, M. and Iwata, Y.: Numerical simulation model for quantitative management of aquaculture, Ecological modeling, Vol.72, pp.21-40, 1994.

6) Hevia, M., Rosenthal, H. and Gowen, R. J.: Modelling benthic deposition under fish cages. J.Appl. Ichthyol, Vol.12, pp.71-74, 1996.

7) Doglioli, A. M., Magaldi, M. G., Vezzulli, L. and Tucci, S.: Development of a numerical model to study the dispersion of wastes coming from a marine fish farm in the Ligurian Sea, Aquaculture, Vol.231, pp.215-235, 2004.

8) Trieu, T.T.N, Giang, L.S. and Lu, M.: Numerical Simulation of Pollutant Transport from Fish Farming In River, Journal of Japan Society of Civil Engineers, Ser. B1 (Hydraulic Engineering), Vol.67, No. 4, pp.I223-I228, 2010.

9) Van Rijn, L. C.: Sediment Transport, Part II: Suspended
Load Transport. Journal of Hydraulic Enginering, ASCE, Vol.110, No. 12, 1984.

10)Hanh, T.T.H.: Application Gis To Establish The Monitoring Network Of Water Quality Basa Catfish Pond At AnGiang, Science \& Technology Development, Vol.12, No.02, 2009.

11) Douglas, J. J. and Gunn, J. E.: A general formulation of alternating direction methods - Part I. parabolic and hyperbolic problems, Numerische Mathematik, Vol.6,pp.428-453, 1964.

12) Magill, S.H., Thetmeyer, H. \& Cromey, C.J.: Settling velocity of faecal pellets of gilthead sea bream(Sparus aurata L.) and sea bass (Dicentrarchus labrax L.) and sensitivity analysis using measured data in a deposition model. Aquaculture, Vol.251, 295-305, 2006.

13) Lefebvre, S., Bacher, C., Meuret, A., Hussenot, J.: Modeling approach of nitrogen and phosphorus exchanges at the sediment-water interface of an intensive fishpond system. Aquaculture, Vol.195, 279-297, 2001.

14) Van Rijn, L. C.: Mathematical modelling of morphological processes in the case of suspended sediment transport. Delft Hydraulics Communication No.382, 1987.

15) VASEP: Market report, 2008.

16) Giang L. S.: MK4 - A Software for Hydraulic and Substances Transport Computation in River, Symp. Fluid Mech. and Natural Disaster Prevent, DaLat,, 1999.

17) Hanh, T. T. H.: Building scientific foundation of establishing monitor network of surface water quality for An Giang's catfish culture area, Master thesis, 110 pp., 2008.

18) APHA: Standard Methods for the Examination of Water and Wastewater, $20^{\text {th }}$ ed., Washington D.C., U. S. A. 1998.

19) MSTE: Vietnam standard 7209:2000, Soil quality. 2000.

20) Ackerfors, H. and Enell, M.: Discharge of nutrients from Swedish fish farming to adjacent sea areas, Ambio, Vol. 19, No.1, pp. 28-35, 1990.

21) WWF: Draft pangasius aquaculture dialogues standard, 2008.

(Received September 30, 2012) 